\title{
An Algorithm to find the Irreducible Polynomials over Galois Field $G F\left(p^{m}\right)$
}

\author{
J K M Sadique Uz Zaman \\ Department of Radio Physics \\ and Electronics, \\ University of Calcutta, \\ Kolkata - 700009, India
}

\author{
Sankhanil Dey \\ Department of Radio Physics \\ and Electronics, \\ University of Calcutta, \\ Kolkata - 700009, India
}

\author{
Ranjan Ghosh \\ Department of Radio Physics \\ and Electronics, \\ University of Calcutta, \\ Kolkata - 700009, India
}

\begin{abstract}
Irreducible Polynomials over $\mathrm{GF}\left(\mathrm{p}^{\mathrm{m}}\right)$ and the multiplicative inverses under it are important in cryptography. Presently the method of deriving irreducible polynomials of a particular prime modulus is very primitive and time consuming. In this paper, in order to find all irreducible polynomials, be it monic or non-monic, of all prime moduli $\mathrm{p}$ with all its order $\mathrm{m}$, a fast deterministic computer algorithm based on an algebraic method producing a $(\mathrm{m} \times \mathrm{m})$ matrix is proposed. The maximum number of terms in each column of the matrix is $2^{\mathrm{j}}$ where $\mathrm{j}$ is the column index.
\end{abstract}

\section{General Terms}

Algorithms, Irreducible polynomial.

\section{Keywords}

Extended Finite field, Finite field, Galois field, $\operatorname{GF}\left(7^{3}\right)$, Irreducible polynomial, Multiplicative inverse.

\section{INTRODUCTION}

A basic polynomial $\mathrm{B}(\mathrm{x})$ over finite field or Galois Field $\mathrm{GF}\left(\mathrm{p}^{\mathrm{m}}\right)$ is expressed as,

$$
\mathrm{B}(\mathrm{x})=\mathrm{a}_{\mathrm{m}} \mathrm{x}^{\mathrm{m}}+\mathrm{a}_{\mathrm{m}-1} \mathrm{x}^{\mathrm{m}-1}+\cdots+\mathrm{a}_{1} \mathrm{x}+\mathrm{a}_{0}
$$

$B(x)$ has $(m+1)$ terms, where $a_{m}$ is non-zero and is termed as the leading coefficient [1]. A polynomial is monic if $a_{m}$ is unity, else it is non-monic. A finite field $\mathrm{GF}\left(\mathrm{p}^{\mathrm{m}}\right)$ is called Extension field if $m>1$. The algorithm presented in this paper is true for Extension field.

The $\mathrm{GF}\left(\mathrm{p}^{\mathrm{m}}\right)$ have $\left(\mathrm{p}^{\mathrm{m}}-\mathrm{p}\right)$ elemental polynomials, $\mathrm{b}(\mathrm{x})$ ranging from $p$ to $\left(p^{m}-1\right)$ each of whose representation involves $\mathrm{m}$ terms with leading coefficient $\mathrm{a}_{\mathrm{m}-1}$. The expression of $b(x)$ is written as,

$$
\mathrm{b}(\mathrm{x})=\mathrm{a}_{\mathrm{m}-1} \mathrm{x}^{\mathrm{m}-1}+--\cdot+\mathrm{a}_{1} \mathrm{x}+\mathrm{a}_{0}
$$

where $\mathrm{a}_{1}$ to $\mathrm{a}_{\mathrm{m}-1}$ are not simultaneously zero.

Many of the $\mathrm{B}(\mathrm{x})$, which has an elemental polynomial, $\mathrm{b}(\mathrm{x})$ as a factor under $\mathrm{GF}\left(\mathrm{p}^{\mathrm{m}}\right)$, are termed as reducible. Those of the $\mathrm{B}(\mathrm{x})$ that have no factors are termed as irreducible polynomials $\mathrm{I}(\mathrm{x})$ and is expressed as [1], [2],

$$
\mathrm{I}(\mathrm{x})=\mathrm{a}_{\mathrm{m}} \mathrm{x}^{\mathrm{m}}+\mathrm{a}_{\mathrm{m}-1} \mathrm{x}^{\mathrm{m}-1}+\cdots+\mathrm{a}_{1} \mathrm{x}+\mathrm{a}_{0}, \text { where } \mathrm{a}_{\mathrm{m}} \neq 0 .
$$

Under $\mathrm{GF}\left(\mathrm{p}^{\mathrm{m}}\right)$, the basic polynomials of degree $\mathrm{m}$ vary from $p^{m}$ to $\left(p^{m+1}-1\right)$ while the elemental polynomials are those varying from $\mathrm{p}$ to $\left(\mathrm{p}^{\mathrm{m}}-1\right)$. Some of the basic polynomials are irreducible, since it has no elemental polynomial as a factor. The conventional method to look for an irreducible polynomial is to systematically multiply two or more elemental polynomials under $\mathrm{GF}\left(\mathrm{p}^{\mathrm{m}}\right)$ and the composite product polynomials belonging to the list of basic polynomials are cancelled leaving behind the irreducible polynomials [1]. The task involves a tedious effort, happens to be severely time consuming and becomes herculean in nature with increasing values of $\mathrm{p}$ and $\mathrm{m}$. Following the said method the monic irreducible polynomials for few values of $p=2,3,5$ and 7 are listed in literatures [1], [2] where maximum values of $m$ are taken respectively as $11,7,5$ and 4 .

It is mentioned in [3] that following Inclusion-Exclusion principle of Galois Field, a non-monic irreducible polynomial is computed by multiplying a monic irreducible polynomial by $\alpha$ where $\alpha \in \mathrm{GF}(\mathrm{p})$ and assumes values from 2 to $(\mathrm{p}-1)$. In literatures, to the best knowledge of the present authors, there is no mention of a paper in which the composite polynomial method is translated into an algorithm and in turn into a computer program.

Since 1967 researchers took algorithmic initiatives, followed by computational time-complexity analysis, to factorize basic polynomials on $\mathrm{GF}\left(\mathrm{p}^{\mathrm{m}}\right)$ with a view to get irreducible polynomials, many of them are probabilistic [4], [5], [6], [7] in nature and few of them are deterministic [8], [9]. One may note that the deterministic algorithms are able to find all irreducible polynomials, while the probabilistic ones are able to find many, but not all. However, the composite polynomial approach is a straightforward deterministic method, although time-consuming.

The irreducible polynomial over $\operatorname{GF}\left(2^{8}\right)$ was first used in cryptography for designing an invertible S-Box of AES [10], [11], [12]. The technique involves finding all multiplicative inverses under an irreducible polynomial is available in [13], [14], [15], [16].

In this paper we propose a computer algorithm based on an algebraic method which searches irreducible polynomials among basic polynomials over $\operatorname{GF}\left(\mathrm{p}^{\mathrm{m}}\right)$. The algorithm is deterministic since it is able to find all the irreducible polynomials over $\mathrm{GF}\left(\mathrm{p}^{\mathrm{m}}\right)$ in a short time.

For convenient understanding, the proposed algebraic method is presented in Sec. 2 for any value of $p$ with $m=3$. The method can find all monic and non-monic irreducible polynomials $\mathrm{I}(\mathrm{x})$ of all $\mathrm{B}(\mathrm{x})$ over $\mathrm{GF}\left(\mathrm{p}^{\mathrm{m}}\right)$. In Sec. 3 it is demonstrated that the proposed searching algorithm actually searches much less number of elemental polynomials to find all the irreducible polynomials over $\mathrm{GF}\left(\mathrm{p}^{\mathrm{m}}\right)$. The conclusion is in Sec. 4.

\section{ALGEBRAIC METHOD TO FIND IRREDUCIBLE POLYNOMIALS OVER GF $\left(\mathbf{p}^{\mathbf{m}}\right)$}

The basic idea of the algebraic method is to form a k-matrix of order $(\mathrm{m} \times \mathrm{m})$ involving coefficients of $\mathrm{b}(\mathrm{x})$ and $\mathrm{B}(\mathrm{x})$ based on an assumption that the multiplicative inverses of an elemental polynomial $\mathrm{b}(\mathrm{x})$ under a basic polynomial $\mathrm{B}(\mathrm{x})$ over $\mathrm{GF}\left(\mathrm{p}^{\mathrm{m}}\right)$ exists. If the determinant of the k-matrix, i.e. $\operatorname{det}(\mathrm{k})$, is non-zero for all the $b(x)$, one can conclude that the polynomial $\mathrm{B}(\mathrm{x})$ is an irreducible polynomial $\mathrm{I}(\mathrm{x})$. In the 
event the $\operatorname{det}(\mathrm{k})$ is zero at least for one $\mathrm{b}(\mathrm{x})$, the concerned $\mathrm{B}(\mathrm{x})$ is reducible. For better clarity of understanding, the generalized algebraic method for any value of $\mathrm{p}$ is worked out in Sec. 2.1 with $m=3$. The formation of k-matrix of order $(3 \times 3)$ is presented in Sec. 2.2 for $m=3$. One can also refer [17] for understanding of k-matrix. It is interesting to note that column-wise elements of the k-matrix have a generalized similar pattern for $\mathrm{m}-$ the patterns are presented in Sec.2.3 for $2 \leq \mathrm{m} \leq 5$.

\subsection{Algebraic Method to find Irreducible Polynomials over GF $\left(\mathbf{p}^{\mathrm{m}}\right)$ with $\mathbf{m}=3$}

Here $B(x)=\left(a_{3} x^{3}+a_{2} x^{2}+a_{1} x+a_{0}\right)$ is a polynomial over $\mathrm{GF}\left(7^{3}\right)$ and $\mathrm{b}(\mathrm{x})=\left(\mathrm{b}_{2} \mathrm{x}^{2}+\mathrm{b}_{1} \mathrm{x}+\mathrm{b}_{0}\right)$ is an elemental polynomial under $\mathrm{B}(\mathrm{x})$. If $\mathrm{c}(\mathrm{x})=\left(\mathrm{c}_{2} \mathrm{x}^{2}+\mathrm{c}_{1} \mathrm{x}+\mathrm{c}_{0}\right)$ is the multiplicative inverse of the polynomial $b(x)$, one can write,

$$
[\mathrm{b}(\mathrm{x}) \mathrm{c}(\mathrm{x})] \bmod \mathrm{B}(\mathrm{x})=1
$$

or, $\left[\left(b_{2} x^{2}+b_{1} x+b_{0}\right)\left(c_{2} x^{2}+c_{1} x+c_{0}\right)\right] \bmod \left(a_{3} x^{3}+a_{2} x^{2}\right.$

$$
\left.+a_{1} x+a_{0}\right)=1
$$

Here, one can get the values for $c_{0}, c_{1}$ and $c_{2}$ by solving eq.(1) as follows:

$$
\begin{aligned}
& {\left[b_{2} c_{2} x^{4}+\left(b_{1} c_{2}+b_{2} c_{1}\right) x^{3}+\left(b_{0} c_{2}+b_{1} c_{1}+b_{2} c_{0}\right) x^{2}+\left(b_{0} c_{1}+\right.\right.} \\
& \left.\left.\mathrm{b}_{1} \mathrm{c}_{0}\right) \mathrm{x}+\mathrm{b}_{0} \mathrm{c}_{0}\right] \bmod \left(\mathrm{a}_{3} \mathrm{x}^{3}+\mathrm{a}_{2} \mathrm{x}^{2}+\mathrm{a}_{1} \mathrm{x}+\mathrm{a}_{0}\right)=1 \\
& \text { or, }\left[a_{3}{ }^{-1} b_{2} c_{2} x\left(a_{3} x^{3}+a_{2} x^{2}+a_{1} x+a_{0}\right)+\left(b_{1} c_{2}+b_{2} c_{1}-\right.\right. \\
& \left.a_{3}{ }^{-1} a_{2} b_{2} c_{2}\right) x^{3}+\left(b_{0} c_{2}+b_{1} c_{1}+b_{2} c_{0}-a_{3}^{-1} a_{1} b_{2} c_{2}\right) x^{2}+ \\
& \left.\left(b_{0} c_{1}+b_{1} c_{0}-a_{3}{ }^{-1} a_{0} b_{2} c_{2}\right) x+b_{0} c_{0}\right] \bmod \left(a_{3} x^{3}+a_{2} x^{2}+\right. \\
& \left.\mathrm{a}_{1} \mathrm{x}+\mathrm{a}_{0}\right)=1 \\
& \text { or, }\left[a_{3}{ }^{-1}\left(b_{1} c_{2}+b_{2} c_{1}-a_{3}{ }^{-1} a_{2} b_{2} c_{2}\right)\left(a_{3} x^{3}+a_{2} x^{2}+a_{1} x+a_{0}\right)+\right. \\
& \left(b_{0} c_{2}+b_{1} c_{1}+b_{2} c_{0}-a_{3}{ }^{-1} a_{1} b_{2} c_{2}-a_{3}{ }^{-1} a_{2} b_{1} c_{2}-a_{3}{ }^{-1} a_{2} b_{2} c_{1}\right. \\
& \left.+a_{3}^{-2} a_{2}^{2} b_{2} c_{2}\right) x^{2}+\left(b_{0} c_{1}+b_{1} c_{0}-a_{3}{ }^{-1} a_{0} b_{2} c_{2}-a_{3}{ }^{-1} a_{1} b_{1} c_{2}-\right. \\
& \left.a_{3}{ }^{-1} a_{1} b_{2} c_{1}+a_{3}{ }^{-2} a_{1} a_{2} b_{2} c_{2}\right) x+\left(b_{0} c_{0}-a_{3}{ }^{-1} a_{0} b_{1} c_{2}-\right. \\
& \left.\left.a_{3}{ }^{-1} a_{0} b_{2} c_{1}+a_{3}{ }^{-2} a_{0} a_{2} b_{2} c_{2}\right)\right] \bmod \left(a_{3} x^{3}+a_{2} x^{2}+a_{1} x+\right. \\
& \left.\mathrm{a}_{0}\right)=1 \\
& \text { or, }\left[\left\{\left(a_{3}^{-2} a_{2}^{2} b_{2}-a_{3}{ }^{-1} a_{1} b_{2}-a_{3}^{-1} a_{2} b_{1}+b_{0}\right) c_{2}+\left(b_{1}-\right.\right.\right. \\
& \left.\left.a_{3}^{-1} a_{2} b_{2}\right) c_{1}+b_{2} c_{0}\right\} x^{2}+\left\{\left(a_{3}^{-2} a_{1} a_{2} b_{2}-a_{3}{ }^{-1} a_{0} b_{2}-\right.\right. \\
& \left.\left.a_{3}{ }^{-1} a_{1} b_{1}\right) c_{2}+\left(b_{0}-a_{3}{ }^{-1} a_{1} b_{2}\right) c_{1}+b_{1} c_{0}\right\} x+\left\{\left(a_{3}{ }^{-2} a_{0} a_{2} b_{2}-\right.\right. \\
& \left.\left.\left.a_{3}{ }^{-1} a_{0} b_{1}\right) c_{2}-a_{3}{ }^{-1} a_{0} b_{2} c_{1}+b_{0} c_{0}\right\}\right] \bmod \left(a_{3} x^{3}+a_{2} x^{2}+\right. \\
& \left.a_{1} x+a_{0}\right)=1
\end{aligned}
$$

From eq.(2) it is evident that the dividend is smaller than the divisor. Hence to satisfy the required condition, i.e., the remainder $=1$, in this equation the following properties must hold.

(i) The constant part $\equiv 1 \bmod$ p.

(ii) The coefficients of $x \equiv 0 \bmod p$.

(iii) The coefficients of $x^{2} \equiv 0 \bmod p$.

Therefore,

$$
\begin{aligned}
& \left\{\left(a_{3}{ }^{-2} a_{0} a_{2} b_{2}-a_{3}{ }^{-1} a_{0} b_{1}\right) c_{2}-a_{3}{ }^{-1} a_{0} b_{2} c_{1}+b_{0} c_{0}\right\} \bmod p=1 \quad(3 a) \\
& \left\{\left(a_{3}{ }^{-2} a_{1} a_{2} b_{2}-a_{3}{ }^{-1} a_{0} b_{2}-a_{3}{ }^{-1} a_{1} b_{1}\right) c_{2}+\left(b_{0}-a_{3}{ }^{-1} a_{1} b_{2}\right) c_{1}+\right. \\
& \left.\quad b_{1} c_{0}\right\} \bmod p=0
\end{aligned}
$$

$$
\begin{gathered}
\left\{\left(a_{3}{ }^{-2} a_{2}{ }^{2} b_{2}-a_{3}{ }^{-1} a_{1} b_{2}-a_{3}{ }^{-1} a_{2} b_{1}+b_{0}\right) c_{2}+\right. \\
\left.\left(b_{1}-a_{3}{ }^{-1} a_{2} b_{2}\right) c_{1}+b_{2} c_{0}\right\} \bmod p=0
\end{gathered}
$$

Rearranging terms as coefficients of $\mathrm{c}_{0}, \mathrm{c}_{1}$ and $\mathrm{c}_{2}$, the eq. (3) becomes as follows after considering the fact that -1 is equivalent to $(\mathrm{p}-1)$ in modular arithmetic with modulus $\mathrm{p}$, since the algebra is being worked out in $\mathrm{GF}\left(\mathrm{p}^{3}\right)$ :

$$
\begin{gathered}
{\left[b_{0} c_{0}+\left\{0+(p-1) a_{3}{ }^{-1} a_{0} b_{2}\right\} c_{1}+\{0+0\right.} \\
\left.\left.(p-1) a_{3}{ }^{-1} a_{0} b_{1}+a_{3}{ }^{-2} a_{0} a_{2} b_{2}\right\} c_{2}\right] \bmod p=1 \\
{\left[b_{1} c_{0}+\left\{b_{0}+(p-1) a_{3}{ }^{-1} a_{1} b_{2}\right\} c_{1}+\left\{0+(p-1) a_{3}{ }^{-1} a_{0} b_{2}+\right.\right.} \\
\left.\left.(p-1) a_{3}{ }^{-1} a_{1} b_{1}+a_{3}{ }^{-2} a_{1} a_{2} b_{2}\right\} c_{2}\right] \bmod p=0 \\
{\left[b_{2} c_{0}+\left\{b_{1}+(p-1) a_{3}{ }^{-1} a_{2} b_{2}\right\} c_{1}+\left\{b_{0}+(p-1) a_{3}{ }^{-1} a_{1} b_{2}+\right.\right.} \\
\left.\left.(p-1) a_{3}{ }^{-1} a_{2} b_{1}+a_{3}{ }^{-2} a_{2} a_{2} b_{2}\right\} c_{2}\right] \bmod p=0
\end{gathered}
$$

\subsection{Formation of $(\mathrm{m} \times \mathrm{m}) \mathrm{K}$-Matrix for $\mathrm{m}=3$}

In order to form k-matrix, the above eq.(4) can be written as,

$$
\begin{aligned}
& \left(\mathrm{k}_{00} \mathrm{c}_{0}+\mathrm{k}_{01} \mathrm{c}_{1}+\mathrm{k}_{02} \mathrm{c}_{2}\right) \bmod \mathrm{p}=1 \\
& \left(\mathrm{k}_{10} \mathrm{c}_{0}+\mathrm{k}_{11} \mathrm{c}_{1}+\mathrm{k}_{12} \mathrm{c}_{2}\right) \bmod \mathrm{p}=0 \\
& \left(\mathrm{k}_{20} \mathrm{c}_{0}+\mathrm{k}_{21} \mathrm{c}_{1}+\mathrm{k}_{22} \mathrm{c}_{2}\right) \bmod \mathrm{p}=0
\end{aligned}
$$

where k-values are known and these are equal to,

$$
\left.\left.\begin{array}{c}
\mathrm{k}_{00}=\left(\mathrm{b}_{0}\right) \bmod \mathrm{p} \\
\mathrm{k}_{01}=\left((\mathrm{p}-1) \mathrm{a}_{3}{ }^{-1} \mathrm{a}_{0} \mathrm{~b}_{2}\right) \bmod \mathrm{p} \\
\mathrm{k}_{02}=\left((\mathrm{p}-1) \mathrm{a}_{3}{ }^{-1} \mathrm{a}_{0} \mathrm{~b}_{1}+\mathrm{a}_{3}{ }^{-2} \mathrm{a}_{0} \mathrm{a}_{2} \mathrm{~b}_{2}\right) \bmod \mathrm{p}
\end{array}\right\} \begin{array}{c}
\mathrm{k}_{10}=\left(\mathrm{b}_{1}\right) \bmod \mathrm{p} \\
\mathrm{k}_{11}=\left(\mathrm{b}_{0}+(\mathrm{p}-1) \mathrm{a}_{3}{ }^{-1} \mathrm{a}_{1} \mathrm{~b}_{2}\right) \bmod \mathrm{p} \\
\mathrm{k}_{12}=\left((\mathrm{p}-1) \mathrm{a}_{3}{ }^{-1} \mathrm{a}_{0} \mathrm{~b}_{2}+(\mathrm{p}-1) \mathrm{a}_{3}{ }^{-1} \mathrm{a}_{1} \mathrm{~b}_{1}+\right. \\
\left.\mathrm{a}_{3}{ }^{-2} \mathrm{a}_{1} \mathrm{a}_{2} \mathrm{~b}_{2}\right) \bmod \mathrm{p} \\
\mathrm{k}_{20}=\left(\mathrm{b}_{2}\right) \bmod \mathrm{p} \\
\mathrm{k}_{21}=\left(\mathrm{b}_{1}+(\mathrm{p}-1) \mathrm{a}_{3}{ }^{-1} \mathrm{a}_{2} \mathrm{~b}_{2}\right) \bmod \mathrm{p} \\
\mathrm{k}_{22}\left(\mathrm{~b}_{0}+(\mathrm{p}-1) \mathrm{a}_{3}{ }^{-1} \mathrm{a}_{1} \mathrm{~b}_{2}+(\mathrm{p}-1) \mathrm{a}_{3}{ }^{-1} \mathrm{a}_{2} \mathrm{~b}_{1}+\right. \\
\left.\mathrm{a}_{3}{ }^{-2} \mathrm{a}_{2} \mathrm{a}_{2} \mathrm{~b}_{2}\right) \bmod \mathrm{p}
\end{array}\right\}
$$

The eq.(5), i.e., $(\mathrm{k} \times \mathrm{c}) \bmod \mathrm{p}=\mathrm{V}$ can be solved by using matrix method as,

$$
\mathrm{c}=\left(\mathrm{k}^{-1} \times \mathrm{V}\right) \bmod \mathrm{p}
$$

where,

$$
\begin{gathered}
\mathrm{V}=\left(\begin{array}{c}
1 \\
0 \\
0
\end{array}\right), \quad \mathrm{k}=\left(\begin{array}{lll}
\mathrm{k}_{00} & \mathrm{k}_{01} & \mathrm{k}_{02} \\
\mathrm{k}_{10} & \mathrm{k}_{11} & \mathrm{k}_{12} \\
\mathrm{k}_{20} & \mathrm{k}_{21} & \mathrm{k}_{22}
\end{array}\right) \\
\mathrm{k}^{-1}=\left(\begin{array}{ccc}
\mathrm{k}_{00} & \mathrm{ik}_{01} & \mathrm{ik}_{02} \\
\mathrm{ik} \mathrm{k}_{10} & \mathrm{ik_{11 }} & \mathrm{ik_{12 }} \\
\mathrm{ik} \mathrm{k}_{21} & \mathrm{ik_{22 }}
\end{array}\right), \mathrm{c}=\left(\begin{array}{c}
\mathrm{c}_{0} \\
\mathrm{c}_{1} \\
\mathrm{c}_{2}
\end{array}\right)=\left(\begin{array}{c}
\mathrm{ik}_{00} \\
\mathrm{ik_{10 }} \\
\mathrm{ik_{20 }}
\end{array}\right)
\end{gathered}
$$

While calculating $\mathrm{k}^{-1}$ from $\mathrm{k}$-matrix, one has to ensure that the determinant $\operatorname{det}(\mathrm{k})$ is non-zero. In the event $\operatorname{det}(\mathrm{k})=0$, the $\mathrm{B}(\mathrm{x})$ is a reducible polynomial and the multiplicative inverses of its elements does not exist. If $\operatorname{det}(\mathrm{k})$ is non-zero for all the elements, the $\mathrm{B}(\mathrm{x})$ is irreducible and the multiplicative inverses of elements exist. By calculating $\mathrm{k}^{-1}$ from $\mathrm{k}$-matrix 
given in eq.(8), one can get solution for $\mathrm{c}_{0}, \mathrm{c}_{1}$ and $\mathrm{c}_{2}$. In such a case one can write,

$$
\begin{gathered}
\left(b_{2} x^{2}+b_{1} x+b_{0}\right)^{-1}=\left(c_{2} x^{2}+c_{1} x+c_{0}\right) \bmod \left(a_{3} x^{3}+\right. \\
\left.a_{2} x^{2}+a_{1} x+a_{0}\right)
\end{gathered}
$$

\subsection{Generalized Column-Wise Patterns of K-Matrix Elements}

Following the workouts of the algebraic method for $2 \leq \mathrm{m} \leq 5$ for the purpose of forming $(\mathrm{m} \times \mathrm{m}) \mathrm{k}$-matrix, if $\mathrm{k}_{\mathrm{ij}}$ terms are organized in $m$ columns with $0 \leq$ both $(i, j) \leq(m-1)$, one notices algebraic similarities up to $(\mathrm{m}-1)^{\text {th }}$ columns and a new term emerges in the $m^{\text {th }}$ column. The $\mathrm{k}_{\mathrm{ij}}$ terms for $\mathrm{m}=5$ are shown below,

$$
\begin{aligned}
& 1^{\text {st }} \text { column }(j=0): \\
& k_{i j}=b_{i-0 .} \\
& 2^{\text {nd }} \text { column }(j=1): \\
& k_{i j}=b_{i-1}+\left(-a_{m}{ }^{-1}\right)\left[a_{i-0} b_{m-1}\right] . \\
& 3^{\text {rd }} \text { column }(j=2): \\
& k_{i j}=b_{i-2}+\left(-a_{m}{ }^{-1}\right)\left[a_{i-1} b_{m-1}+a_{i-0} b_{m-2}\right]+ \\
& \quad\left(-a_{m}{ }^{-1}\right)^{2}\left[a_{i-0} a_{m-1} b_{m-1}\right] . \\
& 4^{\text {th }} \text { column }(j=3): \\
& k_{i j}=b_{i-3}+\left(-a_{m}{ }^{-1}\right)\left[a_{i-2} b_{m-1}+a_{i-1} b_{m-2}+a_{i-0} b_{m-3}\right]+ \\
& \quad\left(-a_{m}{ }^{-1}\right)^{2}\left[b_{m-1}\left\{a_{i-1} a_{m-1}+a_{i-0} a_{m-2}\right\}+a_{i-0} a_{m-1} b_{m-2}\right]+ \\
& \quad\left(-a_{m}{ }^{-1}\right)^{3}\left[a_{i-0} a_{m-1} a_{m-1} b_{m-1}\right] . \\
& 5^{\text {th }} \text { column }(j=4): \\
& k_{i 4}=b_{i-4}+\left(-a_{m}{ }^{-1}\right)\left[a_{i-3} b_{m-1}+a_{i-2} b_{m-2}+a_{i-1} b_{m-3}+a_{i-0} b_{m-4}\right]+ \\
& \quad\left(-a_{m}{ }^{-1}\right)^{2}\left[b_{m-1}\left(a_{i-2} a_{m-1}+a_{i-1} a_{m-2}+a_{i-0} a_{m-3}\right)+\right. \\
& \left.\quad \quad b_{m-2}\left(a_{i-1} a_{m-1}+a_{i-0} a_{m-2}\right)+a_{i} a_{m-1} b_{m-3}\right]+ \\
& \quad\left(-a_{m}{ }^{-1}\right)^{3}\left[a_{m-1} b_{m-1}\left(a_{i-1} a_{m-1}+a_{i-0} a_{m-2}\right)+\right. \\
& \left.\quad a_{i} a_{m-1}\left(a_{m-2} b_{m-1}+a_{m-1} b_{m-2}\right\}\right]+ \\
& \left.{ }^{-1}\right)^{4}\left[a_{i-0} a_{m-1} a_{m-1} a_{m-1} b_{m-1}\right] .
\end{aligned}
$$

The similarities of $k_{i j}$ expressions indicate, (1) First and second columns are respectively for $1^{\text {st }}$ and $2^{\text {nd }}$ columns for $2 \leq$ $m \leq 5$, (2) Third column is the same for $3 \leq m \leq 5$, (3) Fourth column is also the same for $4 \leq \mathrm{m} \leq 5$ and (4) Fifth column is for $\mathrm{m}=5$ only.

Notes:

(1) If suffix of any term in $\mathrm{j}^{\text {th }}$ column is negative, the concerned term is zero.

(2) In k-matrix, maximum number of terms in $\mathrm{j}^{\text {th }}$ column of $(\mathrm{m}-1)^{\text {th }}$ row is $2^{\mathrm{j}}$.

\section{IRREDUCIBLE POLYNOMIALS OVER GF $\left(p^{m}\right)$ : A SEARCHING} ALGORITHM

From the algebraic method presented in Sec. 2, it is evident that one has to check the $\operatorname{det}(\mathrm{k})$ of the $\mathrm{k}$-matrix for all the elemental polynomials $\mathrm{b}(\mathrm{x})$ for a particular $\mathrm{B}(\mathrm{x})$. It is interesting to note that in actual computation, one can serve the purpose by having necessary checks much lesser in number. The rationality of adopting reduced number of checks is presented in Sec. 3.1. The related pseudo-code of the program algorithm is described in Sec. 3.2.The results of computation of irreducible polynomials for first six prime moduli are given in Sec. 3.3.

\subsection{Reduced Number of Checks over Elemental Polynomials}

For $\mathrm{B}(\mathrm{x})$ over $\mathrm{GF}\left(7^{3}\right)$, there are 336 elemental polynomials from 7 to 342 out of which 7 to $\left(7^{2}-1\right)$, i.e. 42 are linear and $7^{2}$ to $\left(7^{3}-1\right)$, i.e. 294 are quadratic, while the basic polynomials have $7^{3}$ to $\left(7^{4}-1\right)$, i.e. there are 2058 cubic polynomials. The reducible $\mathrm{B}(\mathrm{x})$ of degree 3 must be composed either of a product of a linear and a quadratic polynomial or of a product of three linear polynomials. Hence, it is sufficient if $\operatorname{det}(\mathrm{k})$ is checked for 42 times over linear elemental polynomials only. The $\mathrm{B}(\mathrm{x})$ over $\mathrm{GF}\left(7^{4}\right)$ are 4-degree polynomials and reducible $\mathrm{B}(\mathrm{x})$ must be composed of a product either of a linear and a cubic polynomials or of two quadratic polynomials or of four linear polynomials. Hence its reducibility checks can be limited only to linear and quadratic elemental polynomials. Considering the said feature, one can define a parameter $r$ as,

$$
r=\left\lfloor\frac{m}{2}\right\rfloor+1
$$

and keep the checks from $\mathrm{p}$ to $\left(\mathrm{p}^{\mathrm{r}}-1\right)$. It may be noted that for a particular $B(x), b(x)$ is searched $\left(p^{r}-p\right)$ number of times, instead of $\left(\mathrm{p}^{\mathrm{m}}-\mathrm{p}\right)$ and that the maximum degree of the factoring elemental polynomial $\mathrm{b}(\mathrm{x})$ to be checked is $\left\lfloor\frac{m}{2}\right\rfloor$.

\subsection{Pseudo-Code of the Program Algorithm}

A new algorithm is proposed in this paper to find the irreducible polynomials over $\mathrm{GF}\left(\mathrm{p}^{\mathrm{m}}\right)$ where $\mathrm{p}$ is a prime modulus and index $\mathrm{m}$ is an integer. The pseudo-code of the algorithm is given below.

\section{Pseudo-code of proposed algorithm:}

Inputs: $\mathrm{p}$ and $\mathrm{m}$.

$$
\begin{aligned}
& r=\left\lfloor\frac{m}{2}\right\rfloor+1 \\
& \text { For } \mathrm{Bx}=\mathrm{p}^{\mathrm{m}} \text { to } \mathrm{p}^{\mathrm{m}+1}-1
\end{aligned}
$$

Convert $\mathrm{Bx}$ into its equivalent p-base number and store them in an array a[ ] defined in eq.(1) where $a_{0}$ is the least significant digit.

For $b x=p$ to $p^{r}-1$

Convert the bx into its equivalent $\mathrm{p}$-base number and store them in an array $b[$ ] defined in eq.(1) where $b_{0}$ is the least significant digit.

From arrays $a[$ ] and $b[$ ] form the $(m \times m)$ k-matrix described in eq.(8).

Calculate determinant of the k-matrix $\operatorname{det}(\mathrm{k})$.

If $\operatorname{det}(\mathrm{k})=0$

Current $\mathrm{Bx}$ is reducible.

Break.

Else

$$
\text { If } b x=p^{r}-1
$$




\section{Current $\mathrm{Bx}$ is irreducible.}

End of $b x$

\section{End of $\mathrm{Bx}$}

\subsection{Results of Computation}

The computation is undertaken for monic as well as nonmonic irreducible polynomials for the first six prime moduli with $\mathrm{m}=2,3$ and 4 . It is observed that the results of monic irreducible polynomials for first four prime moduli are identical to what is given in [1], [2]. It is also observed that all the non-monic polynomials are in conformity with what is stated in [3]. For prime moduli 11 and 13, there is no mention of irreducible polynomials in literatures. The monic irreducible polynomials for $\mathrm{p}=11$ and 13 with $\mathrm{m}=2,3$ and 4 are obtained and their results for $p=11$ and 13 with $m=2$ and 3 are given in Appendix A while the whole list are uploaded in [18]. Their non-monic polynomials are also found to be in conformity with what is stated in [3].

\section{CONCLUSION}

The proposed computer algorithm searching all irreducible polynomials over $\mathrm{GF}\left(\mathrm{p}^{\mathrm{m}}\right)$ is fast. The computation of 7098 monic irreducible polynomials from among 28561 basic monic polynomials over $\mathrm{GF}\left(13^{4}\right)$ is undertaken practically in no time in the computing system available to the authors (Pentium(R) 4 CPU, 2.00GHz, $768 \mathrm{MB}$ of RAM, Windows XP Service Pack 2, Compiler Turbo C 3.0).

At present, for all irreducible polynomials with $\mathrm{p}=2$, one can find multiplicative inverses of all elemental polynomials for all values of $\mathrm{m}$ following Extended Euclidean Algorithm (EEA). It is observed that for irreducible polynomials with p>2 one cannot find multiplicative inverses of all elemental polynomials using EEA [17]. With little modification, the proposed algorithm can find multiplicative inverses of all irreducible polynomials for $\mathrm{p}>2$ with any value of $\mathrm{m}$.

In Sec. 2.3 the $\mathrm{k}_{\mathrm{ij}}$ expressions are presented in five columns for $m=5$. Looking at the algebraic expression of the $\mathrm{m}^{\text {th }}$ column of a particular $m$ and comparing it with that of the (m$1)^{\text {th }}$ column of the previous $\mathrm{m}$, it might be possible to predict the algebraic expression of the $(\mathrm{m}+1)^{\text {th }}$ column for the next $\mathrm{m}$, based on some induction rule. This requires further futuristic initiatives.

\section{ACKNOWLEDGMENTS}

We express our gratitude towards the DST, New Delhi and the TEQIP (Phase-II), University of Calcutta for providing financial support respectively to the first author and the second author. We are also indeed thankful to the Head of the Department of Radio Physics and Electronics, University of Calcutta for providing necessary infrastructural facilities to undertake research activities.

\section{REFERENCES}

[1] Lidl R., Niederreiter H., Finite Fields, Encyclopedia of Mathematics and its Applications, Vol. 20, AddisonWesley Publishing Company, 1983.
[2] Church R., "Tables of Irreducible Polynomials for the first four Prime Moduli", Annals of Mathematics, Vol. 36(1), pp. 198 - 209, January, 1935.

[3] Chebolu S.K. and Minac. J., "Counting Irreducible Polynomials over Finite Fields Using the InclusionExclusion Principle", Math. Mag., Vol.84(5), pp. 369 371, 2011.

[4] Berlekamp E. R., "Factoring Polynomial over finite fileds", Bell Syst. Tech. J., Vol. 46, pp. 1853 - 1859, 1967.

[5] Adleman L.M. and Lenstra H.W., "Finding irreducible polynomials over finite fields", Proc. 18th ACM Conf. on The Theory of Computing, Berkeley, CA, pp. $350-$ 355., 1986.

[6] Cantor D.G., "On Arithmetical Algorithms over Finite Fields" J. Combinatorial Theory Series A 9, pp. 285 300 (1989).

[7] Bach E. and Shoup V., "Factoring Polynomials using Random Bits”, J. Symbolic Computation, Vol 9, pp. 229 $-239,1990$.

[8] Berlekamp E. R., "Factoring Polynomial over large finite fileds", Math. Comput. Vol. 24 (11), pp. 713 - 735 , 1970.

[9] Shoup, V., "New algorithms for finding irreducible polynomials in finite fields", Math. Comput. Vol. 54, pp. $435-447,1990$.

[10] Daemen J., Rijmen V., AES Proposal: Rijndael, AES Algorithm Submission, September 3, 1999.

[11] FIPS Pub. 197, Announcing the Advanced Encryption Standard (AES), November 26, 2001.

[12] Stinson D.R., Cryptography Theory and Practice (Boca Raton, Chapman \& Hall, CRC, 3rd Edition, 2006).

[13] Stallings W., Cryptography and Network Security Principles and Practices, Delhi, Pearson Education, 4th Edition, 2008.

[14] Forouzan B.A., Mukhopadhyay D., Cryptography and Network Security, New Delhi, TMH, 2nd Edition, 2011.

[15] Hasan M.A., "Double-Basis Multiplicative Inversion Over GF( $\left.2^{\mathrm{m}}\right)$ ", IEEE Trans. Comp., Vol. 47,(9), pp. 960 $-970,1998$.

[16] Arguello F., "Lehmer-based algorithm for computing inverses in Galois fields $\mathrm{GF}\left(2^{\mathrm{m}}\right)$ ", Electronics Letters, Vol. 42(5), 2006.

[17] Zaman JKM. S. and Ghosh R., "Multiplicative Polynomial Inverse over $\mathrm{GF}\left(7^{3}\right)$ : Crisis of EEA and its Solution", Applied Computation and Security Systems, Advances in Intelligent Systems and Computing, Volume 305, pp. 87 - 107, DOI: 10.1007/978-81-3221988-0_6.

[18] https://www.academia.edu/attachments/34220711/downl oad_file 


\section{Appendix A \\ Irreducible polynomials over $\mathrm{GF}\left(11^{2}\right), \mathrm{GF}\left(11^{3}\right)$, GF $\left(13^{2}\right)$ and $G F\left(13^{3}\right)$}

1. In $\mathbf{G F}\left(\mathbf{1 1}^{2}\right)$ : Total number of irreducible polynomial is 55

$101,103,104,105,109,111,114,116,117,118,122,124$, $125,126,12 \mathrm{~A}, 133,136,138,139,13 \mathrm{~A}, 142,145,147,148$, $149,151,152,153,157,15 \mathrm{~A}, 161,162,163,167,16 \mathrm{~A}, 172$, $175,177,178,179,183,186,188,189,18 \mathrm{~A}, 192,194,195$, 196, 19A, 1A1, 1A4, 1A6, 1A7, 1A8.

2. In $\mathbf{G F}\left(\mathbf{1 1}^{3}\right)$ : Total number of irreducible polynomial is 440

1014, 1015, 1016, 1017, 1022, 1024, 1027, 1029, 1032, 1035, 1036, 1039, 1041, 1044, 1047, 104A, 1051, 1053, 1058, $105 \mathrm{~A}, 1063,1065,1066,1068,1071,1072,1079,107 \mathrm{~A}$, $1081,1085,1086,108 \mathrm{~A}, 1092,1093,1098,1099,10 \mathrm{~A} 3$, 10A4, 10A7, 10A8, 1102, 1103, 1105, 1106, 1112, 1113, $1117,1119,1123,1124,1129,112 \mathrm{~A}, 1131,1132,1138,1139$, $1156,1157,1158,1159,1162,1164,1168,116 \mathrm{~A}, 1171,1174$, $1175,1178,1182,1184,1187,118 \mathrm{~A}, 1194,1196,1198$, 119A, 11A3, 11A5, 11A6, 11A8, 1202, 1204, 1205, 1207, $1215,1216,1218,1219,1223,1225,1229,122 \mathrm{~A}, 1233,1234$, $1239,123 \mathrm{~A}, 1241,1242,1245,1246,1267,1268,1269$, $126 \mathrm{~A}, 1272,1274,1277,1279,1282,1283,1286,128 \mathrm{~A}$, 1291, 1294, 1296, 1299, 12A1, 12A3, 12A5, 12AA, 1303, 1304, 1308, 130A, 1311, 1312, 1317, 1318, 1323, 1324, 1327, $1328,1346,1347,1348,1349,1351,1355,1357,135 \mathrm{~A}, 1362$, 1366, 1369, 136A, 1371, 1374, 1376, 1379, 1383, 1385, 1387, 1389, 1391, 1392, 1394, 139A, 13A6, 13A7, 13A9, 13AA, 1401, 1405, 1407, 140A, 1412, 1413, 1416, 141A, 1421, 1423, 1426, 1429, 1434, 1436, 1438, 143A, 1444, 1446, 1447, $1449,1454,1455,1457,1458,1461,1465,1466,146 \mathrm{~A}, 1472$, $1473,1477,1478,1482,1483,1486,1487,14 \mathrm{~A} 2,14 \mathrm{~A} 3$, $14 \mathrm{~A} 4,14 \mathrm{~A} 5,1501,1502,1508,1509,1525,1526,1527$, $1528,1531,1533,1536,1538,1542,1543,1546,154 \mathrm{~A}, 1552$, $1555,1557,155 \mathrm{~A}, 1561,1563,1565,1567,1575,1577,1578$, 157A, 1581, 1582, 1589, 158A, 1593, 1594, 1598, 159A, 15A4, 15A5, 15A9, 15AA, 1602, 1603, 1609, 160A, 1623, $1624,1625,1626,1633,1635,1638,163 \mathrm{~A}, 1641,1645,1648$, $1649,1651,1654,1656,1659,1664,1666,1668,166 \mathrm{~A}, 1671$, $1673,1674,1676,1681,1682,1689,168 \mathrm{~A}, 1691,1693,1697$, 1698, 16A1, 16A2, 16A6, 16A7, 1701, 1704, 1706, 170A, $1711,1715,1718,1719,1722,1725,1728,172 \mathrm{~A}, 1731,1733$, $1735,1737,1742,1744,1745,1747,1753,1754,1756,1757$, 1761, 1765, 1766, 176A, 1773, 1774, 1778, 1779, 1784, 1785, 1788, 1789, 17A6, 17A7, 17A8, 17A9, 1801, 1803, 1807, $1808,1813,1814,1819,181 \mathrm{~A}, 1823,1824,1827,1828,1842$, $1843,1844,1845,1851,1854,1856,185 \mathrm{~A}, 1861,1862,1865$, 1869, 1872, 1875, 1877, 187A, 1882, 1884, 1886, 1888, 1891, 1897, 1899, 189A, 18A1, 18A2, 18A4, 18A5, 1904, 1906, 1907, 1909, 1912, 1913, 1915, 1916, 1921, 1922, 1926, 1928, 1931, 1932, 1937, 1938, 1945, 1946, 1949, 194A, 1961, 1962, 1963, 1964, 1972, 1974, 1977, 1979, 1981, 1985, 1988, 1989, 1992, 1995, 1997, 199A, 19A1, 19A6, 19A8, 19AA, 1A05, 1A06, 1A08, 1A09, 1A12, 1A14, 1A18, 1A19, 1A21, 1A22, 1A27, 1A28, 1A32, 1A33, 1A39, 1A3A, 1A52, 1A53, 1A54, 1A55, 1A61, 1A63, 1A67, 1A69, 1A73, 1A76, 1A77, 1A7A, 1A81, 1A84, 1A87, 1A89, 1A91, 1A93, 1A95, 1A97, 1AA3, 1AA5, 1AA6, 1AA8.

\section{In GF $\left(\mathbf{1 3}^{2}\right)$ : Total number of irreducible polynomial is 78}

102, 105, 106, 107, 108, 10B, 112, 113, 114, 115, 118, 11C, $123,126,127,128,129,12 \mathrm{C}, 131,134,135,136,137,13 \mathrm{~A}$, $142,146,149,14 \mathrm{~A}, 14 \mathrm{~B}, 14 \mathrm{C}, 151,155,158,159,15 \mathrm{~A}, 15 \mathrm{~B}$, $161,162,163,164,167,16 \mathrm{~B}, 171,172,173,174,177,17 \mathrm{~B}$,
181, 185, 188, 189, 18A, 18B, 192, 196, 199, 19A, 19B, 19C, 1A1, 1A4, 1A5, 1A6, 1A7, 1AA, 1B3, 1B6, 1B7, 1B8, 1B9, $1 \mathrm{BC}, 1 \mathrm{C} 2,1 \mathrm{C} 3,1 \mathrm{C} 4,1 \mathrm{C} 5,1 \mathrm{C} 8,1 \mathrm{CC}$.

4. In $\mathbf{G F}\left(\mathbf{1 3}^{3}\right)$ : Total number of irreducible polynomial is 728

1002 , 1003, 1004, 1006, 1007, 1009, 100A, 100B, 1015, $1016,1017,1018,1022,1024,1029,102 \mathrm{~B}, 1035,1036,1037$, $1038,1041,1044,1049,104 \mathrm{C}, 1052,1054,1059,105 \mathrm{~B}$, $1062,1064,1069,106 \mathrm{~B}, 1073,1076,1077,107 \mathrm{~A}, 1083$, $1086,1087,108 \mathrm{~A}, 1095,1096,1097,1098,10 \mathrm{~A} 1,10 \mathrm{~A} 4$, 10A9, 10AC, 10B3, 10B6, 10B7, 10BA, 10C1, 10C4, 10C9, $10 \mathrm{CC}, 1102,1107,110 \mathrm{~A}, 110 \mathrm{C}, 1113,1115,1119,111 \mathrm{~B}$ $1121,1125,1127,112 \mathrm{C}, 1132,1135,1136,1139,1141,1142$, $1145,114 \mathrm{~B}, 1159,115 \mathrm{~A}, 115 \mathrm{~B}, 115 \mathrm{C}, 1161,1164,1169$, $116 \mathrm{C}, 1172,1173,1176,117 \mathrm{C}, 1181,1184,1186,1189$, 1193, 1194, 1195, 1197, 1198, 119A, 119B, 119C, 11A2, $11 \mathrm{~A} 3,11 \mathrm{~A} 4,11 \mathrm{~A} 5,11 \mathrm{~B} 2,11 \mathrm{~B} 4,11 \mathrm{~B} 8,11 \mathrm{BA}, 11 \mathrm{C} 7,11 \mathrm{C} 8$, 11C9, 11CA, 1202, 1203, 1204, 1205, 1211, 1213, 1216, $121 \mathrm{~B}, 1223,1225,1229,122 \mathrm{~B}, 1231,1233,1238,123 \mathrm{~A}$, 1241, 1247, 124A, 124B, 1252, 1253, 1256, 125C, 1266, $1267,1268,1269,1272,1275,1277,127 \mathrm{~A}, 1281,1284,1285$, $1288,1292,1294,1297,129 \mathrm{C}, 12 \mathrm{~A} 1,12 \mathrm{~A} 2,12 \mathrm{~A} 4,12 \mathrm{~A} 5$, $12 \mathrm{~A} 6,12 \mathrm{AA}, 12 \mathrm{AB}, 12 \mathrm{AC}, 12 \mathrm{~B} 5,12 \mathrm{~B} 6,12 \mathrm{~B} 7,12 \mathrm{~B} 8,12 \mathrm{C} 1$, $12 \mathrm{C} 3,12 \mathrm{C} 7,12 \mathrm{C} 9,1302,1307,130 \mathrm{~A}, 130 \mathrm{C}, 1312,1315$, $1316,1319,1321,1324,1329,132 \mathrm{C}, 1333,1334,1335,1337$, 1338, 133A, 133B, 133C, 1347, 1348, 1349, 134A, 1351, $1355,1357,135 \mathrm{C}, 1369,136 \mathrm{~A}, 136 \mathrm{~B}, 136 \mathrm{C}, 1371,1374$, $1376,1379,1382,1384,1388,138 \mathrm{~A}, 1393,1395,1399$, 139B, 13A1, 13A2, 13A5, 13AB, 13B2, 13B3, 13B6, 13BC, $13 \mathrm{C} 2,13 \mathrm{C} 3,13 \mathrm{C} 4,13 \mathrm{C} 5,1401,1403,1406,140 \mathrm{~B}, 1411$, 1412, 1413, 1415, 1416, 1418, 1419, 141A, 1421, 1422, 1423, $1424,1432,1434,1438,143 \mathrm{~A}, 1448,1449,144 \mathrm{~A}, 144 \mathrm{~B}$, $1451,1454,1459,145 \mathrm{C}, 1461,1466,1468,146 \mathrm{C}, 1473$, $1475,1479,147 \mathrm{~B}, 1481,1487,148 \mathrm{~A}, 148 \mathrm{~B}, 1494,1497$, 1498, 149B, 14A3, 14A4, 14A5, 14A6, 14B4, 14B7, 14B9, $14 \mathrm{BC}, 14 \mathrm{C} 2,14 \mathrm{C} 8,14 \mathrm{CB}, 14 \mathrm{CC}, 1502,1503,1504,1505$, $1512,1514,1517,151 \mathrm{C}, 1522,1523,1526,152 \mathrm{C}, 1531$, $1533,1536,153 \mathrm{~B}, 1541,1542,1544,1545,1546,154 \mathrm{~A}$, 154B, 154C, 1556, 1557, 1558, 1559, 1563, 1565, 1569, $156 \mathrm{~B}, 1575,1576,1577,1578,1582,1585,1587,158 \mathrm{~A}$, 1591, 1593, 1598, 159A, 15A1, 15A3, 15A7, 15A9, 15B1, $15 \mathrm{~B} 4,15 \mathrm{~B} 5,15 \mathrm{~B} 8,15 \mathrm{C} 1,15 \mathrm{C} 7,15 \mathrm{CA}, 15 \mathrm{CB}, 1602,1603$, $1604,1605,1611,1613,1618,161 \mathrm{~A}, 1626,1627,1628,1629$, $1632,1634,1637,163 \mathrm{C}, 1641,1643,1647,1649,1653,1655$, 1659 , 165B, 1662, 1663, 1666, 166C, 1671, 1674, 1675, $1678,1685,1686,1687,1688,1691,1693,1696,169 \mathrm{~B}$, $16 \mathrm{~A} 1,16 \mathrm{~A} 7,16 \mathrm{AA}, 16 \mathrm{AB}, 16 \mathrm{~B} 2,16 \mathrm{~B} 5,16 \mathrm{~B} 7,16 \mathrm{BA}, 16 \mathrm{C} 1$, $16 \mathrm{C} 2,16 \mathrm{C} 4,16 \mathrm{C} 5,16 \mathrm{C} 6,16 \mathrm{CA}, 16 \mathrm{CB}, 16 \mathrm{CC}, 1708,1709$, $170 \mathrm{~A}, 170 \mathrm{~B}, 1713,1715,171 \mathrm{~A}, 171 \mathrm{C}, 1724,1725,1726$, $1727,1731,1736,1739,173 \mathrm{~B}, 1744,1746,174 \mathrm{~A}, 174 \mathrm{C}$, $1752,1754,1758,175 \mathrm{~A}, 1761,1767,176 \mathrm{~A}, 176 \mathrm{~B}, 1775$, $1778,1779,177 \mathrm{C}, 1785,1786,1787,1788,1792,1797$, 179A, 179C, 17A2, 17A3, 17A6, 17AC, 17B3, 17B6, 17B8, $17 \mathrm{BB}, 17 \mathrm{C} 1,17 \mathrm{C} 2,17 \mathrm{C} 3,17 \mathrm{C} 7,17 \mathrm{C} 8,17 \mathrm{C} 9,17 \mathrm{CB}, 17 \mathrm{CC}$, $1808,1809,180 \mathrm{~A}, 180 \mathrm{~B}, 1811,1816,1819,181 \mathrm{~B}, 1821$, $1827,182 \mathrm{~A}, 182 \mathrm{~B}, 1832,1837,183 \mathrm{~A}, 183 \mathrm{C}, 1841,1842$, $1843,1847,1848,1849,184 \mathrm{~B}, 184 \mathrm{C}, 1854,1855,1856$, 1857, 1862, 1864, 1868, 186A, 1875, 1876, 1877, 1878, 1883, $1886,1888,188 \mathrm{~B}, 1893,1895,189 \mathrm{~A}, 189 \mathrm{C}, 18 \mathrm{~A} 4,18 \mathrm{~A} 6$, 18AA, 18AC, 18B5, 18B8, 18B9, 18BC, 18C2, 18C3, 18C6, 18CC, 1902, 1907, 190A, 190C, 1913, 1914, 1915, 1917, 1918, 191A, 191B, 191C, 1929, 192A, 192B, 192C, 1933, 1935, 1939, 193B, 1942, 1943, 1944, 1945, 1951, 1954, 1959, 195C, 1961, 1965, 1967, 196C, 1972, 1974, 1978, 197A, 1982, 1983, 1986, 198C, 1992, 1995, 1996, 1999, 19A7, 19A8, 19A9, 19AA, 19B1, 19B4, 19B6, 19B9, 19C1, 19C2, 19C5, 19CB, 1A01, 1A03, 1A06, 1A0B, 1A14, 1A17, 1A18, 
1A1B, 1A21, 1A24, 1A29, 1A2C, 1A31, 1A32, 1A33, 1A35, 1A36, 1A38, 1A39, 1A3A, 1A43, 1A44, 1A45, 1A46, 1A51, 1A56, 1A58, 1A5C, 1A61, 1A62, 1A63, 1A64, 1A74, 1A77, 1A79, 1A7C, 1A83, 1A85, 1A89, 1A8B, 1A92, 1A94, 1A98, $1 \mathrm{~A} 9 \mathrm{~A}, 1 \mathrm{AA} 2,1 \mathrm{AA} 8,1 \mathrm{AAB}, 1 \mathrm{AAC}, 1 \mathrm{AB} 1,1 \mathrm{AB} 7,1 \mathrm{ABA}$, $1 \mathrm{ABB}, 1 \mathrm{AC} 8,1 \mathrm{AC} 9,1 \mathrm{ACA}, 1 \mathrm{ACB}, 1 \mathrm{~B} 08,1 \mathrm{~B} 09,1 \mathrm{~B} 0 \mathrm{~A}$, 1B0B, 1B12, 1B17, 1B1A, 1B1C, 1B22, 1B24, 1B28, 1B2A, 1B33, 1B35, 1B3A, 1B3C, 1B42, 1B43, 1B46, 1B4C, 1B51, 1B57, 1B5A, 1B5B, 1B64, 1B65, 1B66, 1B67, 1B73, 1B76, 1B78, 1B7B, 1B85, 1B88, 1B89, 1B8C, 1B91, 1B96, 1B99,
1B9B, 1BA1, 1BA2, 1BA3, 1BA7, 1BA8, 1BA9, 1BAB, 1BAC, 1BB5, 1BB6, 1BB7, 1BB8, 1BC4, 1BC6, 1BCA, 1BCC, 1C01, 1C03, 1C06, 1C0B, 1C12, 1C14, 1C18, 1C1A, $1 \mathrm{C} 21,1 \mathrm{C} 26,1 \mathrm{C} 28,1 \mathrm{C} 2 \mathrm{C}, 1 \mathrm{C} 34,1 \mathrm{C} 37,1 \mathrm{C} 38,1 \mathrm{C} 3 \mathrm{~B}, 1 \mathrm{C} 42$, $1 \mathrm{C} 48,1 \mathrm{C} 4 \mathrm{~B}, 1 \mathrm{C} 4 \mathrm{C}, 1 \mathrm{C} 51,1 \mathrm{C} 52,1 \mathrm{C} 53,1 \mathrm{C} 54,1 \mathrm{C} 61,1 \mathrm{C} 64$, 1C69, 1C6C, 1C71, 1C77, 1C7A, 1C7B, 1C84, 1C87, 1C89, $1 \mathrm{C} 8 \mathrm{C}, 1 \mathrm{C} 91,1 \mathrm{C} 92,1 \mathrm{C} 93,1 \mathrm{C} 95,1 \mathrm{C} 96,1 \mathrm{C} 98,1 \mathrm{C} 99,1 \mathrm{C} 9 \mathrm{~A}$ 1CA8, 1CA9, 1CAA, 1CAB, 1CB3, 1CB5, 1CB9, 1CBB, $1 \mathrm{CC} 3,1 \mathrm{CC} 4,1 \mathrm{CC} 5,1 \mathrm{CC} 6$ 